\title{
Residual pulmonary vasoreactivity to inhaled nitric oxide in patients with severe obstructive pulmonary hypertension and Eisenmenger syndrome
}

\author{
W Budts, N Van Pelt, H Gillyns, M Gewillig, F Van de Werf, S Janssens
}

\begin{abstract}
Objective-To determine whether inhaled NO (iNO) can reduce pulmonary vascular resistance in adults with congenital heart disease and obstructive pulmonary hypertension or Eisenmenger syndrome.

Design-23 patients received graded doses of iNO. Pulmonary and systemic haemodynamic variables and circulating cyclic guanosine monophosphate (cGMP) concentrations were measured at baseline and after 20 and 80 ppm iNO. Patients were considered responders when total pulmonary resistance was reduced by at least $20 \%$, and rebound was defined as a greater than $10 \%$ increase in total pulmonary resistance upon withdrawal from iNO.

Results-In response to $20 \mathrm{ppm}$ iNO, total pulmonary resistance decreased in four patients $(18 \%, 95 \%$ confidence interval (CI), $2 \%$ to $34 \%$ ), while in response to $80 \mathrm{ppm}$ iNO it decreased in six patients $(29 \%, 95 \%$ CI $10 \%$ to $38 \%)$. Systemic blood pressure did not change. Withdrawal resulted in rebound in three patients $(16 \%, 95 \%$ CI $0 \%$ to $32 \%)$ after cessation of $20 \mathrm{ppm}$ iNO, and in six patients $(35 \%, 95 \%$ CI $12 \%$ to $58 \%)$ after cessation of 80 ppm iNO. Patients with predominant right to left shunting did not respond. In all patients cGMP increased from (mean (SD)) 28 (13) $\mu \mathrm{mol} / 1$ at baseline to 55 (30) and 78 (44) $\mu \mathrm{mol} / 1$ after 20 and $80 \mathrm{ppm}$ iNO ( $\mathrm{p}<0.05 \mathrm{v}$ baseline)

Conclusions-NO inhalation is safe and is associated with a dose dependent increase in circulating cGMP concentrations. Pulmonary vasodilatation in response to iNO was observed in $29 \%$ of patients and was influenced by baseline pulmonary haemodynamics. Responsiveness to acute iNO may identify patients with advanced obstructive pulmonary hypertension and Eisenmenger syndrome who could benefit from sustained vasodilator treatment.

(Heart 2001;86:553-558)
\end{abstract}

Keywords: nitric oxide; pulmonary hypertension; Eisenmenger syndrome

Pulmonary hypertension is defined as a persistently raised systolic pulmonary artery pressure of more than $30 \mathrm{~mm} \mathrm{Hg}$, a mean pulmonary artery pressure of more than $20 \mathrm{~mm} \mathrm{Hg}$, and a pulmonary vascular resistance of more than 67 dynes.s. $\mathrm{cm}^{-5} .{ }^{1}$ Increased filling pressure in the left heart, severe obstruction to pulmonary venous return, or thrombotic occlusion of the pulmonary venules cause pulmonary hypertension. It may also be caused by precapillary vasoconstriction associated with hypoxia or high altitude, or by systemic diseases or exposure to toxins, including fenfluramine. ${ }^{2}$ In congenital heart disease with a left to right shunt, the high flow across the pulmonary vascular bed increases shear stress and causes obstructive pulmonary hypertension. When pulmonary artery pressure exceeds systemic arterial pressure, right to left shunting results in the Eisenmenger syndrome. $^{3}$ In rare cases, failure to reduce high intrauterine pulmonary vascular resistance after birth results in persistent neonatal pulmonary hypertension.

The underlying molecular mechanisms involved in the development of pulmonary hypertension remain unknown. The endothelium plays an important role in regulating pulmonary vascular tone and structure by releasing a variety of vasoactive substances. ${ }^{4}$ One of these substances is nitric oxide (NO), ${ }^{5}$ which is synthesised from L-arginine by a class of enzymes termed nitric oxide synthases (NOS). In the vessel wall, NO diffuses from the endothelium to the underlying smooth muscle cells, where it activates soluble guanylate cyclase, increases cyclic guanosine monophosphate (cGMP) concentrations, and activates a cGMP dependent protein kinase. NO/cGMP signalling results in vasorelaxation as well as in the inhibition of migration, proliferation, and matrix production of smooth muscle cells. ${ }^{5}$

$\mathrm{NO} / \mathrm{cGMP}$ signal transduction is significantly altered in patients with pulmonary hypertension. Immunohistochemical studies on lung sections from patients with pulmonary hypertension have shown either decreased or increased NOS immunoreactivity in remodelled pulmonary arteries, which is potentially related to both the underlying aetiology and the degree of pulmonary hypertension. ${ }^{6}$ Reduced endothelial NO production and release have been observed in children with congenital heart disease and abnormal pulmonary haemodynamics. $^{7}$ These observations have raised interest in treatments aimed at increasing $\mathrm{NO}$ availability in the lungs of patients with pulmonary hypertension.

In the adult respiratory distress syndrome, inhaled NO (iNO) has been shown to improve ventilation/perfusion mismatch. ${ }^{8}$ After heart transplantation or valve surgery, iNO can selectively lower pulmonary vascular resistance 
and improve the clinical outcome. ${ }^{9}$ Responsiveness to iNO may also be a prognostic marker in patients being considered for heart transplantation, and it is associated with improved survival after transplantation. ${ }^{10}$ Pharmacological vasodilator treatment has been shown to be more efficient in patients with primary pulmonary hypertension who responded to iNO. ${ }^{11}{ }^{12}$ In newborn infants with persistent pulmonary hypertension, iNO reduces pulmonary hypertension and provides a less invasive therapeutic alternative to extracorporeal membrane oxygenation. ${ }^{13}$ In children with congenital heart disease and a preoperative high left to right shunt, iNO after corrective surgery reduces the shunt fraction and improves oxygenation. ${ }^{14}$

No data are available of the effect of iNO on severe obstructive pulmonary hypertension in adult patients with congenital heart disease. We therefore investigated whether inhalation of NO can detect residual pulmonary vasoreactivity in adults with congenital heart disease with either severe obstructive pulmonary hypertension or Eisenmenger syndrome.

\section{Methods}

SELECTION OF PATIENTS WITH OBSTRUCTIVE

PULMONARY HYPERTENSION

From the start of 1996, we enrolled in the study 23 consecutive adult patients who had congenital heart disease and known or suspected obstructive pulmonary hypertension or Eisenmenger syndrome. Hospital admission was either elective for planned haemodynamic measurements (shunt evaluation, screening for heart-lung transplantation) or when comorbidity occurred. The minimum age was 16 years; an upper age limit was not defined. The ethics committee of the University Hospital Leuven approved the study protocol. All patients gave informed consent.

PULMONARY AND SYSTEMIC HAEMODYNAMIC MEASUREMENTS

The right femoral vein was punctured and an 8 French sheath was placed under local anaesthesia (lignocaine hydrochloride (lidocaine), $5 \mathrm{ml}$ ). A Swan-Ganz catheter with thermistor for continuous cardiac output measurement (Swan-Ganz CCO/VIP, 139HF75, Baxter, Irvine, California, USA) was advanced until a stable wedge position was achieved in either the left or the right pulmonary artery. The correct position of the catheter was confirmed in all patients by the pressure curve and by fluoroscopy.

Pulmonary artery pressure and cardiac output were monitored on-line (Vigilance, model VGS1, Baxter). We measured cardiac output continuously using an intravascular thermodilution probe. ${ }^{15-17}$ Thermodilution measurements using injection of cold fluid cannot provide accurate cardiac output readings in the pulmonary circulation of patients with univentricular hearts, truncus arteriosus, or significant left to right shunts. ${ }^{18}$ Alternatively the Fick method for cardiac output could be used, although measuring oxygen consumption during NO inhalation has not been validated.
Moreover, the obligatory repeated measurements of mixed venous saturation require frequent catheter manipulation, which may not always be technically feasible with complex heart abnormalities. Whenever possible, we compared the continuous cardiac output reading with bolus injections of cold saline and always found a difference of less than $15 \%$.

In the first eight patients we also measured systemic arterial pressure continuously through a 5 French sheath in the right femoral artery. Because blood pressure was unchanged during the study protocol, non-invasive automatic measurements of blood pressure were used for the remaining 15 patients.

Saturation for oxygen was monitored on-line by transcutaneous pulse oximeter (model 504/ 504P, Criticare Systems, Waukesha, Wisconsin, USA). Total pulmonary resistance (mean pulmonary artery pressure divided by cardiac output, in Wood units), cardiac index (cardiac output divided by body surface, in $1 / \mathrm{min} / \mathrm{m}^{2}$ ), and baseline shunt fraction ([systemic saturation minus mixed venous saturation]/ [pulmonary vein saturation minus pulmonary artery saturation] $(\mathrm{Qp} / \mathrm{Qs}))$ were calculated.

NO INHALATION

NO was given through nasal prongs (Salter Labs, Arvin, California, USA) during spontaneous breathing of room air. $\mathrm{NO}$ and $\mathrm{NOx}$ $\left(\mathrm{NO}+\mathrm{NO}_{2}\right)$ were monitored continuously using electrochemical analysis (Nitric Oxide Dosing Unit, Dräger, Lübeck, Germany). NO (20 and $80 \mathrm{ppm}$ ) were given consecutively for 10 minutes. Between the inhalation of each dose and after the $80 \mathrm{ppm}$ NO inhalation, a 10 minute recovery period was observed. Pulmonary and systemic haemodynamic variables were measured at baseline, at the end of the inhalation of $20 \mathrm{ppm} \mathrm{NO}$, after recovery from $20 \mathrm{ppm} \mathrm{NO}$, at the end of the inhalation of 80 ppm NO, and finally after recovery from 80 ppm NO. Total pulmonary vascular resistance and $\mathrm{Qp} / \mathrm{Qs}$ were calculated for each time point.

Patients in whom total pulmonary vascular resistance decreased by more than $20 \%$ after NO were defined as responders to iNO. ${ }^{19}$ Patients in whom total pulmonary resistance increased by more than $10 \%$ after NO withdrawal were defined as having rebound pulmonary hypertension to iNO.

CGMP MEASUREMENTS

Inhaled NO diffuses across the alveolarcapillary membrane to stimulate soluble guanylate cyclase in vascular smooth muscle cells, resulting in increased cGMP production. Increased cGMP production is also reflected in circulating serum concentrations. At each time point after NO inhalation and recovery, serum samples were taken for cGMP measurements, which were done using a commercially available cGMP immunoassay (Amersham, Gent, Belgium).

STATISTICAL ANALYSIS

Descriptive statistics were used to evaluate the characteristics of the study population. Continuous variables were expressed as mean (SD) 
Table 1 Distribution of abnormalities

\begin{tabular}{ll}
\hline & $\begin{array}{l}\text { Number } \\
\text { of cases }\end{array}$ \\
\hline Atrial septal defect & 6 \\
Ventricular septal defect & 4 \\
Persistent arterial duct & 2 \\
Truncus arteriosus & 2 \\
Transposition of the great arteries + VSD & 4 \\
Corrected transposition of the great arteries + VSD & 2 \\
Persistent neonatal pulmonary hypertension & 1 \\
Tetralogy of Fallot & 1 \\
Double outlet right ventricle & 1 \\
\hline VSD, ventricular septal defect. &
\end{tabular}

and proportions were determined by percentages with $95 \%$ confidence intervals (CI). To evaluate changes in global haemodynamics in all patients after 20 and 80 ppm NO inhalation, repeated analysis of variance (ANOVA) testing was performed. Percentages with confidence intervals were used to describe the number of patients who responded to or showed rebound after 20 and 80 ppm NO inhalation. Significance in all cases was defined as $\mathrm{p}<0.05$.

\section{Results}

PATIENT CHARACTERISTICS

We enrolled 23 patients (seven male and 16 female) between January 1996 and January 2000. Their mean (SD) age was 32 (19) years. Details of the underlying aetiology of the congenital heart disease are given in table 1 .

HAEMODYNAMIC MEASUREMENTS AFTER INHALED NO

The baseline haemodynamic characteristics are summarised in table 2 . In one patient no data were available at $20 \mathrm{ppm}$ inhalation for technical reasons. Two patients were unable to finish the complete protocol owing to subjective discomfort, and only inhaled $20 \mathrm{ppm}$ NO. In 18 of 22 patients $(82 \%, 95 \%$ confidence interval (CI) $68 \%$ to $98 \%$ ) residual intracardiac shunting was detected, while 50\% (95\% CI $39 \%$ to $71 \%$ ) presented with predominant intracardiac left to right shunts $(\mathrm{Qp} / \mathrm{Qs}>1 / 1)$.

When the measurements from all patients were combined, systemic and pulmonary haemodynamics remained unchanged after inhalation of 20 and $80 \mathrm{ppm}$ NO (ANOVA, NS). When responsiveness to iNO was investigated in individual patients, total pulmonary vascular resistance was reduced by more than $20 \%$ in four of 22 patients $(18 \%, 95 \%$ CI $2 \%$ to $34 \%$ ) after inhalation of $20 \mathrm{ppm} \mathrm{NO}$, and in six of 21 patients $(29 \%, 95 \%$ CI $10 \%$ to $38 \%)$ after inhalation of $80 \mathrm{ppm}$ NO. In these responders no change in systemic blood pressure was

Table 2 Haemodynamic characteristics

\begin{tabular}{llll}
\hline Variable & Baseline & iNO 20 ppm & iNO 80 ppm \\
\hline Mean PAP (mm Hg) & $72(30)$ & $71(31)$ & $70(31)$ \\
Mean systemic arterial pressure (mm Hg) & $89(22)$ & $89(19)$ & $89(20)$ \\
Capillary $\mathrm{O}_{2}$ saturation (\%) & $87(8)$ & $88(8)$ & $88(7)$ \\
Pulse rate (beats/min) & $81(11)$ & $84(13)$ & $81(11)$ \\
Cardiac output $(1 / \mathrm{min})$ & $6(3)$ & $6(3)$ & $6(3)$ \\
Cardiac index $\left(\mathrm{l} / \mathrm{min} / \mathrm{m}^{2}\right)$ & $3.9(1.9)$ & $3.9(1.8)$ & $3.6(1.5)$ \\
TPR (Wood units) & $16(12)$ & $16(12)$ & $16(12)$ \\
Qp/Qs & $1.3(0.9)$ & NA & NA \\
\hline
\end{tabular}

Values are mean (SD).

iNO, inhaled nitric oxide; NA, not applicable; PAP, pulmonary artery pressure; Qp/Qs, baseline shunt fraction; TPR, total pulmonary vascular resistance.

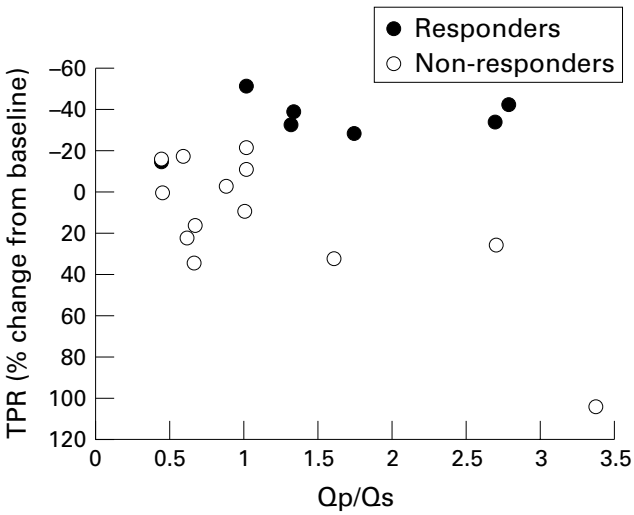

Figure 1 Change in total pulmonary vascular resistance (TPR) (\% baseline) after inhalation of $80 \mathrm{ppm}$ NO. When predominant intracardiac right to left shunting $(Q p / Q s \leqslant 1 / 1)$ was present, TPR did not change after 80 ppm iNO.

Responsiveness to 80 ppm iNO was only found in patients with moderate intracardiac left to right shunts $(Q p / Q s<3 / 1>1 / 1)$.

observed, indicating that iNO acts as a selective pulmonary vasodilator. Total pulmonary vascular resistance remained unchanged in patients with a $Q p / Q s \leqslant 1 / 1$ (fig 1). Data on the rebound phenomenon after discontinuation of iNO were available in 19 patients receiving 20 ppm and 17 patients receiving $80 \mathrm{ppm}$. Total pulmonary vascular resistance increased by more than $10 \%$ in three patients $(16 \%, 95 \%$ CI $0 \%$ to $32 \%$ ) on withdrawal from $20 \mathrm{ppm}$ NO, and in six patients $(35 \%, 95 \%$ CI $12 \%$ to $58 \%)$ on withdrawal from $80 \mathrm{ppm}$ NO. When these data are combined they show that with the higher dose of iNO residual pulmonary vasoreactivity can be demonstrated in about $30 \%$ of patients with congenital heart disease.

\section{cGMP SERUM CONCENTRATIONS AFTER INHALED} $\mathrm{NO}$

cGMP increased significantly from the baseline value of 28 (13) $\mu \mathrm{mol} / 1$ to 55 (30) $\mu \mathrm{mol} / 10$ at 20 $\mathrm{ppm}$ iNO and to $78(44) \mu \mathrm{mol} / 1$ at $80 \mathrm{ppm}$ iNO ( $\mathrm{p}<0.05$, fig 2 ). Haemodynamic responsiveness to iNO did not correlate with changes in circulating cGMP concentrations, because the latter rose proportionately and equally with increasing iNO doses in all patients. This suggests that failure to dilate the pulmonary

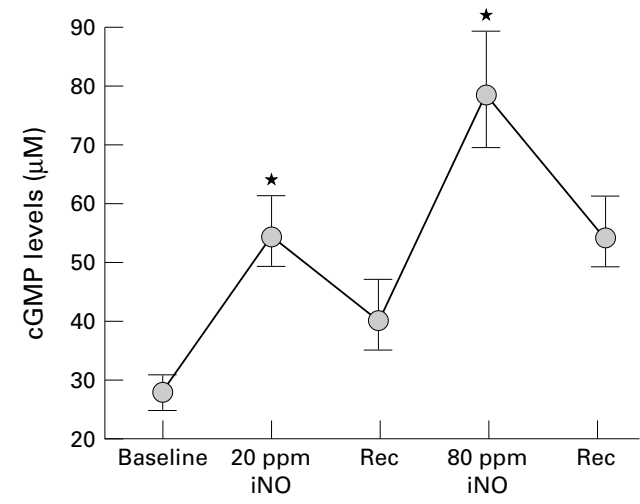

Figure 2 Circulating mean serum cGMP after inhaled NO (iNO). cGMP concentrations after 10 minutes of breathing 20 and 80 ppm NO were significantly higher than at baseline, and decreased after discontinuation of $i N O$. Error bars $=1 S D$. Rec, recovery. ${ }^{\star} p<0.05 v$ baseline cGMP concentrations. 
resistance vessels is not caused by impaired $\mathrm{NO} / \mathrm{cGMP}$ signal transduction. In addition, in patients with rebound pulmonary hypertension to iNO no correlation was found with serum cGMP.

\section{Discussion}

$\mathrm{NO}$ is a potent vasodilator with an important role in the regulation of pulmonary vascular tone. We investigated whether iNO can reduce pulmonary vascular resistance in adult patients with congenital heart disease presenting with obstructive pulmonary hypertension or Eisenmenger syndrome. Mean pulmonary artery pressure and mean systemic blood pressure did not change during graded $\mathrm{NO}$ inhalation. In response to 20 and $80 \mathrm{ppm}$ iNO, total pulmonary resistance decreased in $18 \%$ and $29 \%$ of patients, respectively. Upon withdrawal from NO, rebound pulmonary hypertension was observed in $16 \%$ and $35 \%$, respectively. Patients with predominant intracardiac right to left shunting $(\mathrm{Qp} / \mathrm{Q} s \leqslant 1 / 1)$ did not respond to either dose of iNO (fig 1). Circulating serum cGMP concentrations increased proportionately with increasing doses of iNO in all patients but did not correlate with responsiveness to iNO or rebound after withdrawal of NO. Thus responsiveness to iNO was observed in $30 \%$ of patients with congenital heart disease and obstructive pulmonary hypertension, and may predict further benefit from sustained vasodilator treatment.

Obstructive pulmonary hypertension in patients with congenital heart lesions is caused by increased pulmonary vascular resistance resulting from high blood flow in the pulmonary circulation. ${ }^{20}{ }^{21}$ When pulmonary vascular resistance exceeds systemic vascular resistance, right to left shunting and cyanosis occur, a condition defined as the Eisenmenger syndrome. ${ }^{3}$ The prognosis of these patients with obstructive pulmonary hypertension is better than in patients with primary pulmonary hypertension. ${ }^{22}{ }^{23}$ Medical treatment (calcium channel entry blockers, prostacyclin) for primary pulmonary hypertension is of proven clinical benefit, ${ }^{24-28}$ while the success of medical treatment in children with obstructive pulmonary hypertension remains controversial and varies with age. ${ }^{29-31}$ In older patients, treatment with calcium channel entry blockers is less beneficial and this has stimulated interest in new treatments. One of these is inhalation of NO, a selective pulmonary vasodilator, which reduces the degree of pulmonary hypertension in newborn infants with persistent pulmonary hypertension. ${ }^{13}{ }^{32}$ It remains unknown whether there is a similar therapeutic window for iNO in the growing group of adult patients with obstructive pulmonary hypertension or Eisenmenger syndrome.

In this study, we have for the first time investigated residual pulmonary vasoreactivity to iNO in adults with obstructive pulmonary hypertension. We documented acute responsiveness of the pulmonary vasculature to iNO in $29 \%$ of our patients - more specifically in those with a moderate predominant intracardiac left to right shunt $(\mathrm{Qp} / \mathrm{Qs}>1 / 1)$. Previous case reports have suggested clinical benefit of iNO in specific circumstances. ${ }^{33}{ }^{34}$ For example, a 27 year old woman with Eisenmenger syndrome at 36 weeks' gestation was treated for 48 hours with inhaled nitric oxide because of progressive refractory hypoxaemia during the second stage of labour and in the postpartum period. Nitric oxide inhalation was associated with improved oxygenation and reduced pulmonary artery pressure. ${ }^{34}$

Responsiveness of pulmonary resistance vessels to iNO is theoretically dependent on three different variables: first, NO must reach the alveolar ducts or alveoli; second, NO must diffuse across the alveolar-capillary barrier; and third, target smooth muscle cells of the precapillary resistance vessels must relax upon stimulation of intracellular soluble guanylate cyclase (sGC) by iNO. Our data show that inhalation through nasal prongs can deliver sufficient NO to the lower respiratory tract and across the alveolar-capillary membrane to stimulate cytoplasmatic sGC receptors in target cells, as confirmed by raised cGMP concentrations. In patients with obstructive pulmonary hypertension and a significant residual hyperdynamic component resulting from an intracardiac left to right shunt, lack of responsiveness to iNO may reflect an already maximally vasodilated vascular bed, impeding additional relaxation. High flow through the pulmonary vascular bed causes a shear stress induced increase in NO production, which may blunt the additional vasodilator effects of iNO. Lack of responsiveness to iNO is also observed in patients with fixed pulmonary hypertension (with a high mean pulmonary artery pressure and a predominant right to left shunt), in whom pulmonary target vessels are expected to be extensively remodelled. The molecular basis of vascular unresponsiveness to iNO in the remodelled pulmonary vascular bed remains unknown but may be related to impaired signal transduction downstream of cGMP, to altered phosphodiesterase function, or to a cGMP independent mechanism.

Our observations, made in a relatively small number of patients, only allow preliminary interpretations but may generate useful ideas for future studies. Questions concerning which patients respond to iNO and what biological variables can predict responsiveness remain unresolved. In primary pulmonary hypertension, acute responders to iNO can be treated with systemic vasodilators (calcium channel entry blockers, prostacyclin). ${ }^{11}{ }^{12} 35$ In contrast, in patients with obstructive pulmonary hypertension or Eisenmenger syndrome, vasodilator treatment with calcium channel entry blockers will lower systemic vascular resistance disproportionately more than pulmonary vascular resistance. As a result, there will be increased intracardiac right to left shunting and worsening arterial oxygen saturation. ${ }^{30}$ Prostacyclin may be more selective for pulmonary resistance vessels, and was reported to improve exercise tolerance in patients with primary pulmonary hypertension ${ }^{36-38}$ and in those with Eisenmenger syndrome. ${ }^{39}$ Continuous intravenous administration of vasodilators 
in these chronically instrumented patients may, however, increase the risk of catheter induced paradoxical embolism and infection. Our study suggests that some patients with obstructive pulmonary hypertension benefit from $\mathrm{NO}$ inhalation, particularly those with no predominant intracardiac right to left shunts and moderate intracardiac left to right shunts $(\mathrm{Qp} / \mathrm{Qs}>1 / 1<3 / 1)$. NO diffusing into the bloodstream is readily bound to the haem moiety of haemoglobin in circulating red blood cells, thereby eliminating systemic vasodilatation. ${ }^{40}$ The absence of systemic hypotensive effects is of critical importance in these patients and they may represent a cohort with potential benefit from intensified and sustained selective pulmonary vasodilator treatment.

\section{CONCLUSIONS}

Inhalation of 20 or $80 \mathrm{ppm} \mathrm{NO}$ in patients with obstructive pulmonary hypertension or Eisenmenger syndrome is feasible and safe, and reduces total pulmonary resistance in $30 \%$ of cases. Identification of predictive factors for $\mathrm{NO}$ responsiveness is warranted and requires a prospective study in a larger cohort of patients with congenital heart disease and pulmonary hypertension. Responsiveness to iNO in a subset of patients suggests a therapeutic window for sustained selective pulmonary vasodilator treatment (prostacyclin or NO). Whether prolonged NO treatment can prevent the progression of obstructive pulmonary hypertension, as was recently demonstrated in experimental models, ${ }^{41}$ remains to be determined.

We thank D Vlasselaers MD, of the department of intensive care medicine, the nursing staff of the catheterisation laboratory, and the coronary care unit of the department of cardiology for their the coronary care unit of the department of cardiology for their logistic support. We also thank R Fagard $\mathrm{MD}$, PhD for valuable help with statistical analysis. The study was supported by grants
from the University of Leuven and the Fund for Scientific from the University of Leuven and the Fund for Scientific Research Flanders (to SJ). SJ is a Clinical Investigator for the
Fund for Scientific Research Flanders and holder of a chair Fund for Scientific Research
financed by AstraZeneca Inc.

1 Barratt-Boyes BG, Wood EH. Cardiac output and related measurements and pressure values in the right heart and associated vessels, together with an analysis of the hemodynamic response to the inhalation of high oxygen mixtures in healthy subjects. F Lab Clin Med 1958;51:72-90.

2 Delcroix M, Kurz X, Walckiers D, et al. High incidence of primary pulmonary hypertension associated with appetite suppressants in Belgium. Eur Respir 7 1998;12:271-6.

3 Chandrasekhar KP, Pai KN. Eisenmenger's syndrome. Indian Heart $\mathcal{F}$ 1966;18:66-74.

4 Kouyoumdjian C, Adnot S, Levame M, et al. Continuous inhalation of nitric oxide protects against development of pulmonary hypertension in chronically hypoxic rats. $\mathcal{f}$ Clin pulmonary hypertension

5 Ignarro LJ, Buga GM, Wood KS, et al. Endothelium-derived relaxing factor produced and released from artery and vein is nitric oxide. Proc Natl Acad Sci USA 1987;84:9265-9.

6 Giaid A, Saleh D. Reduced expression of endothelial nitric oxide synthase in the lungs of patients with pulmonary hypertension. N Engl f Med 1995;333:214-21.

7 Celermajer DS, Cullen S, Deanfield JE. Impairment of endothelium-dependent pulmonary artery relaxation in children with congenital heart disease and abnormal pulmonary hemodynamics. Circulation 1993;87:440-6.

8 Rossaint R, Pison U, Gerlach $\mathrm{H}$, et al. Inhaled nitric oxide: its effects on pulmonary circulation and airway smooth muscle cells. Eur Heart f 1993;14(suppl I):133-40.

9 George SJ, Boscoe MJ. Inhaled nitric oxide for right ventricular dysfunction following cardiac transplantation. Br f Clin Pract 1997;51:53-5.

10 Costard-Jackle A, Hill I, Schroeder JS, et al. The influence of preoperative patient characteristics on early and late survival following cardiac transplantation. Circulation 1991; 84:III-329-37.
11 Sitbon $\mathrm{O}$, Humbert $\mathrm{M}$, Jagot JL, et al. Inhaled nitric oxide as a screening agent for safely identifying responders to oral calcium-channel blockers in primary pulmonary hypertension [see comments]. Eur Respir 7 1998;12:265-70.

12 Jolliet P, Bulpa P, Thorens JB, et al. Nitric oxide and prostacyclin as test agents of vasoreactivity in severe precapillary pulmonary hypertension: predictive ability and consequences on haemodynamics and gas exchange. Thorax 1997;52:369-72.

13 Roberts JD, Fineman JR, Morin FC, et al. Inhaled nitric oxide and persistent pulmonary hypertension of the newborn. N Engl f Med 1997;336:605-10.

14 Beghetti M, Habre W, Friedli B, et al. Continuous low dose inhaled nitric oxide for treatment of severe pulmonary hypertension after cardiac surgery in paediatric patients. $\mathrm{Br}$ Heart F 1995;73:65-8.

15 Dollar M, Yelderman ML, Quinn MD, et al. Evaluation of a continuous thermodilution cardiac output catheter. ASAIO F 1992;38:M351-6.

16 Normann RA, Johnson RW, Messinger JE, et al. A continuous cardiac output computer based on thermodilution principles. Ann Biomed Eng 1989;17:61-73.

17 Runciman WB, Ilsley AH, Roberts JG. An evaluation of thermodilution cardiac output measurement using the Swan-Ganz catheter. Anaesth Intensive Care 1981;9:20820 .

18 Weyland A, Wietasch G, Hoeft A, et al. The effect of an intracardiac left-right shunt on thermodilution measurements of cardiac output. An extracorporeal circulation model. Anaesthesist $1955 ; 44: 13-23$

19 Galie N, Ussia G, Passarelli P, et al. Role of pharmacologic tests in the treatment of primary pulmonary hypertension. Am 7 Cardiol 1995;75:55-62A.

20 Perkin RM, Anas NG. Pulmonary hypertension in pediatric patients. F Pediatr 1984;105:511-22.

21 Collins-Nakai RL, Rabinovitch M. Pulmonary vascular obstructive disease. Cardiol Clin 1993;11:675-87.

22 Hopkins WE. Severe pulmonary hypertension in congenital heart disease: a review of Eisenmenger syndrome. Curr Opin Cardiol 1995;10:517-23.

23 Hopkins WE, Ochoa LL, Richardson GW, et al. Comparison of the hemodynamics and survival of adults with severe primary pulmonary hypertension or Eisenmenger syndrome. F Heart Lung Transplant 1996;15:100-5.

24 Rich S, Brundage BH. High-dose calcium channel-blocking therapy for primary pulmonary hypertension: evidence for long-term reduction in pulmonary arterial pressure and regression of right ventricular hypertrophy. Circulation 1987;76:135-41.

25 Rubin LJ. Calcium channel blockers in primary pulmonary hypertension. Chest 1985;88:257-60S

26 Packer M. Therapeutic application of calcium-channel antagonists for pulmonary hypertension. Am $\mathcal{F}$ Cardiol 1985;55:196-201B.

27 Higenbottam T, Wheeldon D, Wells F, et al. Long-term treatment of primary pulmonary hypertension with continuous intravenous epoprostenol (prostacyclin). Lancet 1984;i:1046-7.

28 Barst RJ. Pharmacologically induced pulmonary vasodilatation in children and young adults with primary pulmonary hypertension. Chest 1986;89:497-503.

29 Gildein HP, Wildberg A, Mocellin R. Comparative studies of hemodynamics under prostacyclin and nifedipine in patients with Eisenmenger syndrome. $Z$ Kardiol 1995;83: $55-63$.

30 Roos-Hesselink JW, Meijboom FJ, Spitaels SE. Eisenmenger syndrome in adults. Ned Tijdschr Geneeskd 1999; 143:501-5.

31 Wimmer $M$, Schlemmer $M$. Long-term hemodynamic effects of nifedipine on congenital heart disease with Eisenmenger's mechanism in children. Cardiovasc Drugs Ther 1992;6:183-6.

32 Hoffman GM, Ross GA, Day SE, et al. Inhaled nitric oxide reduces the utilization of extracorporeal membrane oxycenation in persistent pulmonary hypertension of the newborn. Crit Care Med 1997;25:352-9.

33 Lust KM, Boots RJ, Dooris M, et al. Management of labor in Eisenmenger syndrome with inhaled nitric oxide. $A m \mathcal{F}$ Obstet Gynecol 1999;181:419-23.

34 Goodwin TM, Gherman RB, Hameed A, et al. Favorable response of Eisenmenger syndrome to inhaled nitric oxide during pregnancy. Am f Obstet Gynecol 1999;180:64-7.

35 Sitbon O, Brenot F, Denjean A, et al. Inhaled nitric oxide as a screening vasodilator agent in primary pulmonary hypertension. A dose-response study and comparison with prostacyclin. Am f Respir Crit Care Med 1995;151:384-9.

36 Wax D, Garofano R, Barst RJ. Effects of long-term infusion of prostacyclin on exercise performance in patients with primary pulmonary hypertension. Chest 1999;116:914-20.

37 Nagaya N, Uematsu M, Okano Y, et al. Effect of orally active prostacyclin analogue on survival of outpatients with primary pulmonary hypertension. I Am Coll Cardiol 1999; 34:1188-92.

38 Hoeper MM, Olschewski H, Ghofrani HA, et al. A comparison of the acute hemodynamic effects of inhaled nitric oxide and aerosolized iloprost in primary pulmonary hypertension. German PPH study group. $7 \mathrm{Am}$ Coll Cardiol 2000;35:176-82.

39 Rosenzweig EB, Kerstein D, Barst RJ. Long-term prostacyclin for pulmonary hypertension with associated congenital heart defects. Circulation 1999;99:1858-65. 
40 Young JD, Sear JW, Valvini EM. Kinetics of methaemoglobin and serum nitrogen oxide production during inhalation of nitric oxide in volunteers. Br f Anaesth 1996;76: $652-6$
41 Budts W, Pokreisz P, Nong Z, et al. Aerosol gene transfer with inducible nitric oxide synthase reduces hypoxic pulmonary hypertension and pulmonary vascular remodeling in rats. Circulation 2000:102:2880-5.

\section{IMAGES IN CARDIOLOGY}

\section{Unusual multiple spasm during coronary angioplasty}

A 56 year old man was hospitalised for unstable angina. Coronary angiogram revealed a tight and isolated stenosis of the mid right coronary artery (top).

Coronary angioplasty was undertaken following the usual procedure (middle), during which multiple spasms were observed in the proximal and mid segments of the right coronary artery. The patient only felt moderate chest pain, and a modest ST segment elevation in the inferior leads was observed. Fortunately the spasm was successfully treated by intracoronary vasodilators (nitrates and verapamil).

The procedure was completed with two new inflations with a stent-like result (bottom); no immediate complications or long term restenosis occurred.

Though coronary artery spasm has been reported in $1-5 \%$ of balloon angioplasty procedures, it usually occurs at the site of the treated lesions or in the distal vessel. The multiple spasms in the proximal and mid epicardial artery observed in our patient are unusual, and probably resulted from irritation of the artery by the angioplasty equipment.

HERVÉ DOUARD JEAN PAUL BROUSTET hervedouard@wanadoo.fr
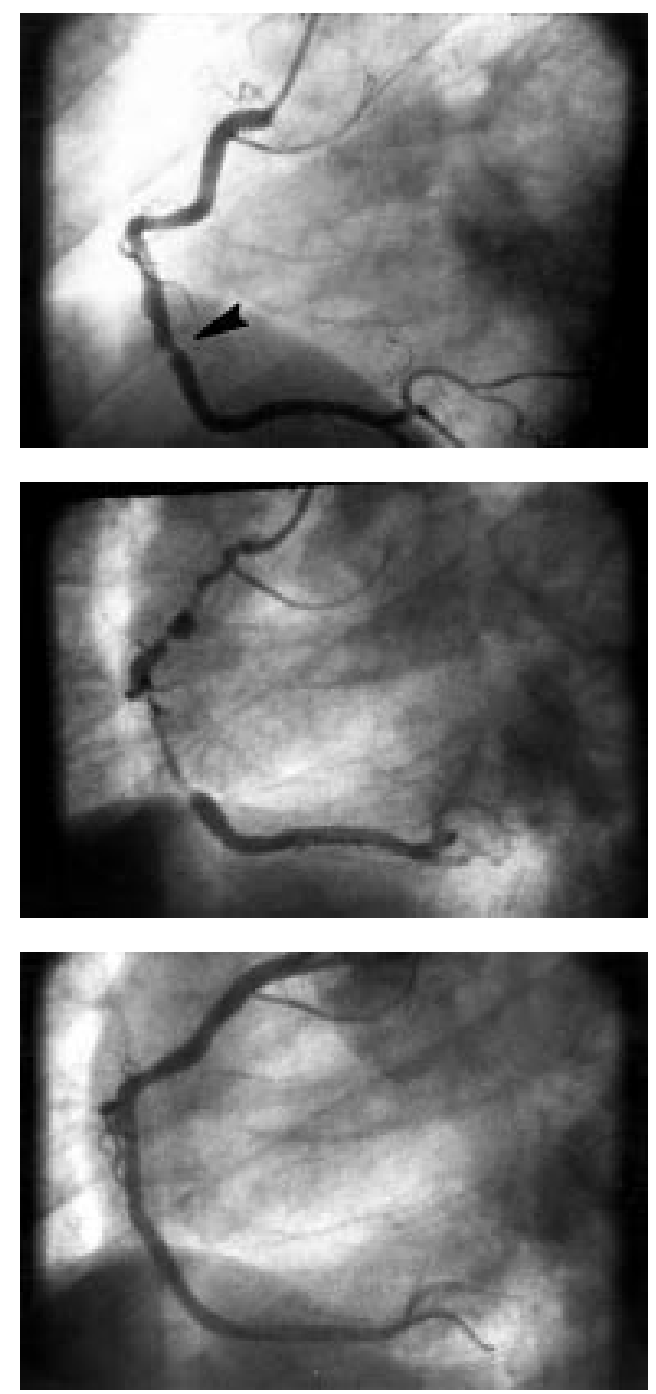